\title{
The Reformation of Age and Ageing
}

\author{
Sarah Harper ${ }^{1}$
}

Published online: 10 August 2017

(C) Springer Science+Business Media B.V. 2017

The 15th April 2017 saw the end of the final living link to the nineteenth century. Emma Morano died at her home in northern Italy aged 117, one of the five longest lived people in recorded history. Emma was born in November 1899 and is believed to have been the last survivor from the nineteenth Century. She survived two world wars and more than 90 Italian governments. Emma is succeeded by Violet Brown, a 117year-old Jamaican woman. None has yet to achieve the longest recorded life, which is still held by Jeanne Calment of France, who died in 1997 aged 122 years, 164 days the longest documented human lifespan.

In the eighteenth century, there were probably 10 centenarians in the whole of Europe, now there are 14,500 just in the UK, and by the end of the century it is projected that there will be close to 1.5 million. There are already over half a million over 90 , and 850 people in the UK over 105. Yet we are still achieving these very long lives without the radical intervention that science can bring, and the recent discussion in Nature ${ }^{1}$ has again highlighted the view that there is currently no reason to suppose that there is a maximum life span.

In recognition of 500 years since Martin Luther asserted his reformations, unleashing unforeseen change across Europe, I was invited to assert a reformation of the reimagining of the concept of age, ageing and old age for the twenty-first century. ${ }^{2}$ I argued not only that our past and present conceptualisations of ageing and old age are at odds with contemporary reality, but that our entire lives - particularly those in advanced economies - are now being played out in a world which is in itself ageing. To grow old in a society which is old is very different from growing old in a society which is young.

\footnotetext{
${ }^{1}$ Nature Volume 546 Number 7660 pp575-696: Brief Communications Arising Contesting the evidence for limited human lifespan Nicholas J. L. Brown, Casper J. Albers \& Stuart J. Ritchie. Many possible maximum lifespan trajectories Bryan G. Hughes \& Siegfried Hekimi. Is there evidence for a limit to human lifespan? Maarten P. Rozing, Thomas B. L. Kirkwood \& Rudi G. J. Westendorp. Questionable evidence for a limit to human lifespan Adam Lenart \& James W. Vaupel. Maximum human lifespan may increase to 125 years Joop de Beer, Anastasios Bardoutsos \& Fanny Janssen

${ }^{2}$ Hay Festival May 2017: a Reformation of Ageing and Old Age
}

Sarah Harper

sarah.harper@ageing.ox.ac.uk

1 Oxford Institute of Population Ageing, University of Oxford, Oxford, UK 
At the turn of the millennium, Europe already had more people over 60 than under 15 . Latin America will have more old than young by 2040, and Asia by 2050. Within 3 years, there will be more people on the planet over 65 than under 5 years old. Within the next decade, half the population of western Europe will be aged over 50. In terms of our own longevity, in 1850 half the people in Britain were dead before they reached their mid-40s now half the population can expect to make it into their $80 \mathrm{~s}$. This shift from predominantly young to predominantly older populations has both broad macro-economic implications as well as important financial consequences for both the public and private sector.

Different regions of the world are experiencing the age shift in different ways and magnitudes. In addition, each is also currently challenged by a particular set of demographic dynamics which are controlling the pace and form of the change. Advanced economies are well along the way of the age structural shift, which has been in progression for a couple of hundred years since the start of the demographic transition in Europe in the mid-eighteenth century. Alongside the general mass ageing of their populations, with a steady increase in both the mean and median ages and in average life expectancy, they are also facing the challenge of extreme low fertility, and low mortality rates amongst the oldest old. While the first is changing their worker to dependent ratio, the second is questioning the ability to care for the large numbers in and approaching extreme frailty.

Japan is often seen as the classic ageing society. Japan's rapid fertility decline in the post 2nd World War period brought its child bearing to the lowest in the world - reaching below replacement in the late 1950 's. It fell to 1.5 in the 1990 s, reaching 1.26 in 2005, returning slightly to its current level of 1.41. Japan also led the world in its mortality decline - with male life expectancy rising from around 50 in the immediate post war years to 68 by the mid-1960s; and female life expectancy increased in that period from 54 to 73. Japan now has the highest life expectancies in the world at 80 for men and 87 for women. Late life expectancy is even higher with male life expectancy at 60 now 23 and for women 29.

Building on the rapid post 2nd World War recovery, Japan established universal pension and health care systems. Initially based on a large accumulated reserve fund, Japan had to shift to a pay-as-you-go system in 1985. More recently in 2004, the government introduced a system of fixed contributions and reduced benefits, to secure the future stability of the scheme in the light of extreme ageing. Even so, the social security system now faces serious financing problems as the number of beneficiaries is increasing at a time when the working population is declining - a simultaneous increase in payments and decrease in revenues. In a similar move, the government has also now introduced a system of long term care insurance, in an attempt to curb the upward spiralling of medical care costs.

The US is also facing considerable budget deficits, in part due to its public social security and health programmes. Future scenarios predict that the deficit will range from between $8 \%$ and $20 \%$ of GDP by 2050 . The UK is in a different situation as there has been a continuous shift towards the older individual bearing the financial responsibility of health and pension costs. Yet here the government has raised state pension age to 66 from 2016, in a direct move to cut the UK budget deficit by some $£ 13$ billion a year. Even Australia - currently experiencing annual surpluses - faces a budget deficit of $\$ 100$ billion dollars in ten years' time, around 4\% of GDP, of which $\$ 30$ billion dollars will arise from increased health care spending.

Yet, the major concerns - public spending on pensions, high dependency ratios between workers and non-workers, increases in health care costs, declining availability of family based care, and a slowdown in consumption due to an increase in older 
people and a decrease in younger people - are based on assumptions developed from the characteristics and behaviours of current older populations. Some of these fears are supported, but many are speculative myths, widespread in public debate, but lacking a robust evidential base. Behind the rhetoric defining dependency and productivity lies the complexity of social and economic behaviour and the ability of societies and individuals to adapt to changing circumstances. It is highly likely that future generations of older adults will have higher levels of human capital - in terms of education, skills and abilities - and that old age, as defined by retirement and dependency will occur at far older ages than currently. In addition, they are all issues which can be addressed by policy, given the political and economic will.

As I earlier highlighted, the challenge for advanced economies is that not only are individuals living longer, they are doing so within a population which is in itself growing older. Young nations have high proportions of economically active individuals with the potential to produce the wealth needed to support dependents, both old and young. However, old populations have a lower proportion of workers and thus the responsibility of providing for old age dependency may increasingly fall to older persons themselves. In addition, societies with a large proportion of their populations in old age have to consider how to redistribute resources away from a focus on younger people towards older people in an equitable manner, both inter-generationally (between the generations) and intra-generationally (within each generation). Increasing decline and dependency within the population, inequalities and equitable redistribution of resources frame the major challenges for advanced economies.

As the percentage of individuals within each age group shifts as we move through the 20th and 21 st centuries, so a wave like bulge forms across the population structure, flowing over time from a large percentage of young dependents or children, through a large percentage of workers, to a large percentage of older dependents. The redistribution of resources through the generations is linked to the economic lifecycle and may be described as the generational economy. This comprises the intergenerational distribution of income or consumption which results from the institutions and mechanisms used by each generation to produce, consume, share and save resources; the economic flow between different generations; and the contract which governs this. The generational economy comprises four distinct activities - producing, consuming, saving and sharing.

Across our lives an individual typically undertakes four different sets of economic activities: producing, consuming, saving and sharing. Consumption takes place across the life cycle, and may be consumption of goods or services. Sharing may be publicly via taxation, which funds education, health care and pensions for example, or privately within families and households. Saving allows assets accumulated at one stage of the life cycle to be used at a later stage, as in paying off a housing loan or creating a retirement pension. In order for standards of living to be sustained, those who are working must generate sufficient resources to fund their own material needs; to transfer resources to both young and old dependents; and to provide for their own future dependency in old age. This is where the changing support ratios as a population ages become important: as the proportion of producers to dependents declines as a society reaches the late stage of the demographic transition. One of the key issues in advanced economies is that while in traditional societies, older people continued to produce well into old age, in modern societies people after retirement consume more than they produce. This consumption takes the form of pensions, health and long term care, and 
the drawdown of assets. That is not to say that older people have not "earned" this drawdown through earlier taxation, pension contributions and the careful housekeeping of their assets, nor to ignore their contribution through unpaid and often unrecorded care, but to note that in a population with a large proportion of retired adults, this will have an economic impact.

It is argued that the economic boom experienced by Japan in the 1960s was related to its demographic dividend. Economic calculations suggest that Japan's proportion of producers grew consistently from the end of the 2nd World War until the 1980s, mirroring the rise of the demographic dividend, and outstripping the proportion of consumers in the population. However, from the 1990s onwards Japan's ageing population took front stage; having experienced a fourfold increase in the percentage of the population aged over 65 in 55 years (5\% in 1950 to $20 \%$ by 2005) and with limited immigration, its population also started to decline in size. As is clear from Japan, the context to the economic challenge is the age-structural change in the population, or the changing composition of ages within a population.

Germany provides another example of an extreme aged society. Though one nation now, its demographic history cannot be disconnected from its political past, in as much as the eastern and western parts of country experienced different fertility and mortality rates, and this is still reflected today. Thus, following unification, the level of total fertility of East Germany was at a low of just 0.77 , and has only recently increased to 1.46 , with West Germany at 1.38. Population ageing has thus progressed faster in the east than in the west of the country, encouraged by strong flows of young outmigration to the west. There is expected to be a fall in the national population level over the coming decades, as well as shrinkage of the labour force from its current 55 million to under 40 million by the middle of the century. Despite unification, the institutions of the past still influence the position of the population today. For example, in the east $100 \%$ of pensioners' income comes from the public purse, as opposed to only $80 \%$ in the west; similarly in the east of the country there is still a strong tradition of unemployment benefits for those older workers out of employment prior to retirement, with around one fifth taking them in the east, and only $8 \%$ in the west.

Clearly, the above concerns are based on a series of assumptions - which should be questioned. As we look to reform ageing and old age in the light of extreme longevity, it is essential that we look to the institutions which currently define ageing and old age - not only to reflect the experiences and realities of a growing proportion of our populations, but also to ensure that our societies continue to distribute resources fairly across the life course. For the individual, of particular importance is the cohort one is born into. ${ }^{3}$ To be born into a small cohort has many advantages over a large birth cohort: there is less competition among your birth peers for the resources of society - less competition for education, for jobs, for housing etc. Yet large birth cohorts may be seen to attract a disproportional amount of societal resources, leading to feelings of intergenerational injustice or even conflict.

We clearly also need to consider the impact of current institutions - and in particular to recognise that twenty-first century living is structured by twentieth century institutions which may not be effective for the twenty-first century dynamics. Our education systems, patterns of work, health care, legal systems, even marriage and families were built during a very different demographic. There are also deep stereotypes and

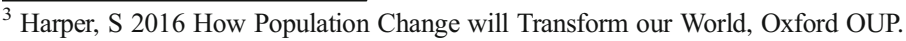


preconceptions around the contribution and burden of older adults which are not supported by robust evidence, and these need to be revisited. Not only because many of them lead to unjust behaviour towards older people, such as ageism, but also because these institutions and perceptions influence the behaviour of older people themselves. It is these institutions and public perceptions which influence the behaviour of individuals in our societies. It is these which need to be reformed.

Acknowledgements This paper is based on the talk A Reformation of Age and Ageing, presented at the Hay Literary Festival, May 2017. 